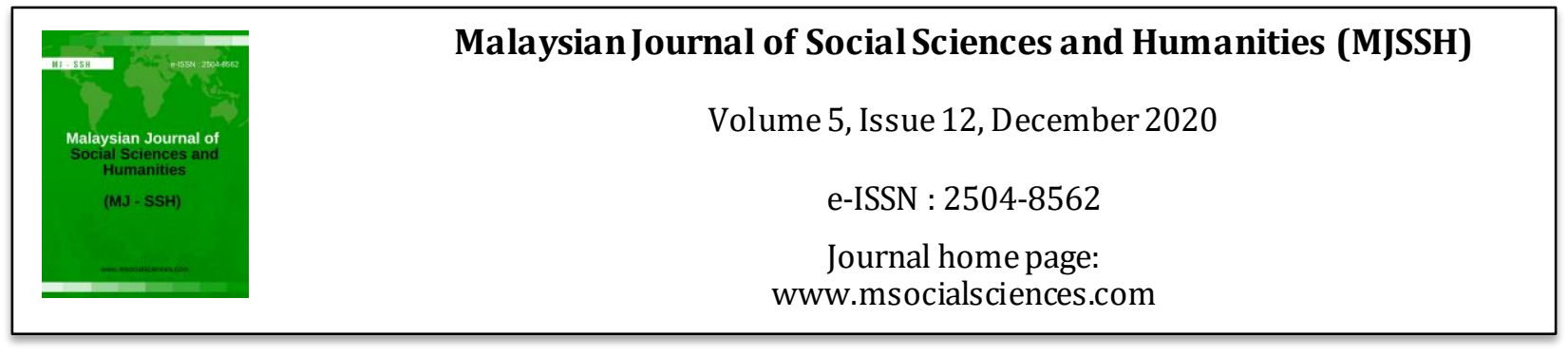

\title{
Integration of ICT in Teaching and Learning of Mathematics: Feature of Systematic Literature
}

\author{
Pearl Kek Jing Wen ${ }^{1}$, Siti Mistima Maat ${ }^{1}$ \\ ${ }^{1}$ Fakulti Pendidikan, Universiti Kebangsaan Malaysia (UKM) \\ Correspondence: Pearl Kek Jing Wen (p99540@siswa.ukm.edu.my)
}

\begin{abstract}
The present study has been developed based on the adoption of ICT in the teaching process of mathematics. There are certain research questions and methods that have been identified in the present study to understand the background of ICT adoption. Review method of the study has been developed based on selection criteria, search strategy and critical appraisal. The review method has helped to identify essential articles based on adoption and challenges of ICT in the education sector. Besides, a critical appraisal has been added in the study which is developed based on ten different themes of ICT integration. Each of the themes has aimed to meet the research questions of the present study. Apart from this, data collection, data analysis has been included in the present study. Moreover, the study has included research findings, recommendations and conclusion.
\end{abstract}

Keywords: ICT, adoption, integration, mathematics, education

\section{Introduction}

The present systematic literature review is going to be on the implementation of information and technology (ICT) in the teaching and learning process of mathematics. The significance of the systematic review approach is to collect adequate information regarding the research topic. ICT system is a way of teaching and learning method where digital tools are used to describe and understand the concepts of the study. The study will discuss the article selection criteria and search process for the systematic literature review. The critical appraisal of the article will be presented along with the data collection method and the data analysis of the articles. Furthermore, some recommendations will be provided for the improvement of the teaching method using ICT.

\section{Review Questions and Scope of Review}

The research questions of this study are addressed below:

i. What is the teacher's level of readiness for integrating ICT in Mathematics teaching?

ii. What are the challenges of using ICT in teaching and learning Mathematics in the classroom among school teachers? 
The focus of the review is to find the level of teachers to adjust to the ICT systems and the major issues regarding the ICT teaching process. ICT is the future of all industries and the learning process as people are rapidly depending on the technologies. Besides, ICT provides better understanding with life examples and also helps to generate better curiosity among the students.

\section{Background of the Study}

ICT is one of the most developed segments for incorporating technologies and in the world changing the teaching style is essential for generating more interest among the students. As discussed in the study by Kim (2018), it is essential to find the different role of ICT in the teaching methods of mathematics. Mathematics is a subject where practical realizations sometimes become really tough to evaluate. This technology helps to build better communication between students and teachers where students can resolve their queries from their teachers without many hazards. According to the study by BuabengAndoh (2015), one of the biggest advantages of ICT is the data management faculty. Using this facility, educational institutes can save their time and cost for storing data of students and teachers. Besides, it helps in teaching process improvement which is a key reason for incorporating ICT.

The dependability of technology is high as it is dependent on digital tools, internets, electricity and many more segments. This study is essential to analyse whether the ICT system is beneficial for the teaching sectors or the issues are more severe than the benefits. As mentioned by Smirnov \& Bogun (2018), the critical analysis of the article will provide guidelines and description of the factors regarding the ICT system in teaching mathematics. The review will provide significant knowledge regarding the advantages and disadvantages of integrating ICT for teaching mathematics. As in recent times analysis of digital technologies is essential before implementation and this will also be useful as ICT is the base of digital technologies.

\section{Review Method}

\section{Selection criteria}

\section{i. Inclusion and exclusion criteria}

In order to select articles, it is identified that the focus of the study is to find the readiness of teachers and issues regarding ICT in teaching mathematics and based on that inclusion and exclusion criteria have been chosen. It has been identified that the issues of ICT systems, advantages of the ICT system and capabilities of teachers to adopt ICT systems are the inclusion criteria. As depicted in the study by Senivongse, Bennet \& Mariano (2017), ICT infrastructure adjustments and capabilities of students to adjust with ICT systems for learning mathematics have been chosen as inclusion criteria to conduct this study. All reviewed articles are based on these criteria and concepts as a part of filtering process of the study.

Exclusion criteria are sections of the research topic where this study is not focused or neglected. The exclusion criteria have been selected as budget for installing ICT systems, government approvals for incorporating ICT and the perspective of parents regarding this new method of teaching mathematics (Werner et al. 2020).

\section{ii. PRISMA model}

In order to select articles, the PRISMA model has been used in this study. The major criteria for rejection are the articles before 2015 and no-peer review journals. Besides, articles have been rejected due to mismatching of language as no languages are accepted other than English \& Bahasa and the ICT systems regarding other aspects than mathematics. This model helps in the filtration process from articles found and it is mentioned below: 
Figure 1: PRISMA model

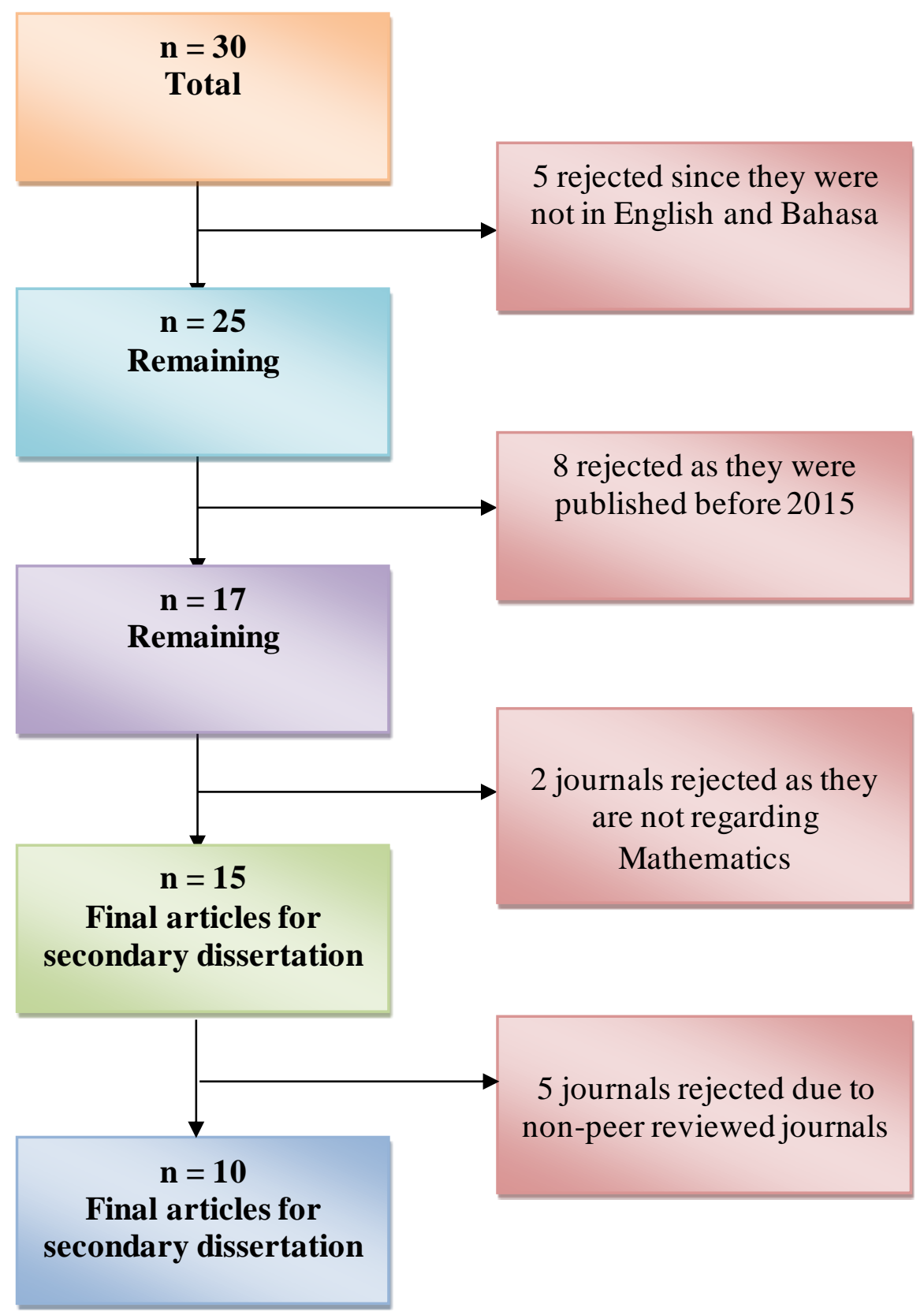

\section{Search strategy}

\section{i. Date of search}

The search process for a suitable article to conduct the study was started on 17 th June 2020 and ended on 20th June 2020. It took around 4 days to search the relevant articles which can provide different perspectives of ICT systems in teaching and learning mathematics. As stated in the study by Schönreiter (2018), it is essential to search for an article that provides information regarding mathematics teaching and thus it took more time.

\section{ii. Searched database}


All the selected articles are peer-review and no manipulation of data has been done to conduct this study. During a search for articles, several databases such as Research Gate, Proquest, Google Scholar, IEEE journals and NCBI note have been used. According to the study by Hsin, Cheng and Tsai (2016), all the journals are analysed and searched mainly based on title name and in order to get peer-reviewed journals with page number, volume number and proper title have been selected.

\section{iii. Terms used for search}

The firsts terms used for searching process is the ICT process and its uses. It was necessary to identify the ICT procedure and thus it was the first aspect for searching. The next essential term is role of ICT in teaching and learning procedures. As ICT is a multi application technology it was imperative to mention particular application of ICT and due to this fact, field of application was mentioned while searching. As mentioned by Thennakoon et al. (2018), the name of the particular subject was necessary and thus the search was limited to the application of ICT in teaching and learning mathematics. The other terms for searching were issues regarding the use of ICT as it was one of $\mathrm{t}$ main focus of the study. Therefore, with the help of these terms, the total search procedure has been conducted.

\section{iv. Overall search process}

The overall search process begins with a search for a relevant article from gathering information. There were suggestions of articles from the mentioned database and these articles were analysed based on their language, date of publication, authenticity and other aspects. As stated by Delavari et al. (2019), all suggested articles were reviewed keeping in mind the review objectives and research questions as well. Based on research objectives, final articles were selected where maximum information and recent data reading the ICT procedures for teaching mathematics were mentioned.

\section{Critical appraisal}

\section{Theme 1: Use of ICT in mathematics classes}

Using the information and communication technology (ICT) for the teaching process has been a relevant topic for the interdisciplinary and subject-specific competencies along with the conditional fields of achievement of school such as individual characteristics of students. As critiqued by Mulenga \& Phiri (2018), the essential aspect to enhance the student's capability in school is school leadership, school strategies, the attitude of teachers and the adoption of ICT. In present times, the adoption of ICT technology has increased the efficiency of the achievements and performance of students. As argued by Mulenga \& Phiri Eickelmann (2017), the adoption of tools and techniques of ICT has the potential to improve the analytical and problem-solving skills of the students.

The overall educational strategy can be enhanced to a certain level with the help of using computers to teach mathematics to students. As critiqued by Mulenga \& Phiri Eickelmann (2017), it is assumed that the long term strategy for the implementation of ICT tools such as educational Master Plan is extremely helpful for improving the learning ability of the students in mathematics classes. It is important to have a multi-step procedure that can utilize considered features. Based on the intercultural and international comparative perspectives, further development of the teaching process is dependent upon the integration of adoption in the classroom (Daher, Baya'a \& Anabousy 2018).

\section{Theme 2: Teaching and learning using tablets in school}

Use of tablets in mathematics class is identified as a crucial change that enhances the teaching and learning process in the education system. In certain times, when teachers are absent in class, tablets can be used to motivate and teach the students through mathematical engagements. As argued by Njurai et 
al. (2017), a major risk associated with the use of tablets in the teaching and learning process is the risk of data security. However, the issue can be reduced significantly by disabling SIM cards. Students can use the tablets by accessing the internet via Wi-Fi service provided by the school authority.

It refers that the use of technology does not cause any security-related issues if it is managed effectively by the school authority. Another challenge of using tablets in the classroom is that collective data cannot be accessed with the help of tablets via Wi-Fi server. As critiqued by Graham, Stols \& Kapp (2020), this technology can only be used when a school has adequate resources and investment for ICT adoption. However, inmates are facilitated by the use of technology to develop web-based mathematical skills. It is extremely important for students in the career development process in fields such as computer science and programming.

\section{Theme 3: Teachers' readiness for ICT integration}

Integration of ICT tools and techniques promises a better quality of teaching and learning process in the education system. The technology is becoming useful and accessible in fulfilling mundane requirements. As cited by Ifinedo, Saarela \& Hämälänen (2019), the usefulness of ICT integration in the teaching process from supporting the traditional roles to substantial support in different sectors such as health, education and businesses. However, the emergence of technology in the educational sectors has changed the dynamics of fostering the learning and teaching process. However, the adoption of ICT in the teaching and learning process is entirely dependent upon the readiness of teachers.

Teacher's readiness for the particular technology is determined by their attitudes, intention and perception. As critiqued by Ogundile et al. (2019), the integration of technology has become extremely important for improving the teaching process. Hence, in order to make the teacher eager to adopt new technology, it is important to conduct training programs. The training programs regarding the functioning of ICT tools would be crucial for making teachers understand the content and usefulness of the technology. As argued by Ifinedo, Saarela \& Hämälänen (2019), the integration of the technology in the teaching process requires the change in the strategies, policies and investments by the school level of governance.

\section{Theme 4: Perception of teachers regarding ICT adoption}

The information and communication technology (ICT) is used by the teachers to gather and share information and data. ICT has become the game-changer in improving the educational system in the 21st Century. The high level of acceptance of ICT tools is dependent upon the positive perception of teachers. As critiqued by Mlambo, Chukwuere \& Ndebele (2018), around 25\% of the teachers in Europe do not find any benefit of using ICT in the teaching and learning process. However, the perception of the students is completely different from the perception of teachers.

It is important to determine and understand the behaviour, beliefs, perception and feelings of ICT for the teachers to utilize ICT in schools. As argued by Qasem \& Nathappa (2016), many of the teachers do not consider them competent enough to integrate or use ICT in the teaching process. The fear of imperfect knowledge and skills regarding the use of technology in mathematics class affect the adoption of technology. The emergence of ICT has changed the way of interaction between the teachers and students. Many of the teachers see the new technologies as an additional burden to the teaching process. Hence, it is essential to change the perception of teachers in order to successfully use ICT in mathematics classes.

\section{Theme 5: Contributing factors to the readiness of mathematics teachers}

ICT is used to promote knowledge sharing and communication among the teachers and students are essential for increasing motivation for learning mathematics. A constructive pedagogy is supported by ICT where students can understand mathematical concepts by exploring the latest technologies. The overall quality of improving mathematics is based on ICT as it can be used in various ways to promote the learning ability of students. According to Apeanti (2016), the major factors that influence the 
readiness of mathematics teachers regarding ICT adoption are teacher's age, TPACK (Technology Pedagogy Content Knowledge), Perception of teachers and Perception regarding the barriers.

Each of the aspects plays a crucial role in the adoption of ICT. As critiqued by Apeanti (2016), it is important for the educational institutions to put in place an education scheme that addresses the professional needs of technology for the perspectives teachers of mathematics. Effective technology training is considered as the major factor that is essential for the teachers to develop a positive perception and attitude towards the integration of ICT in the curriculum. However, as argued by Apeanti (2016), training of technology should not be only focused on the basic skills of computing, but also focused on helping teachers to get connected to pedagogical, technological and content knowledge.

\section{Theme 6: Readiness of schools to integrate ICT in mathematics class}

It has been a long-time topic to use ICT in the teaching process of mathematics which is considered by educators. As critiqued by Kirkok \& Karanja (2018), the readiness of schools to adopt technology is significantly affected by the ratio of personal computers against the numbers of the students and teachers. Due to the lack of technological tools such as computers, a technological gap is retained in the teaching process of schools. It is detrimental to the adoption of ICT in the teaching process as computers are considered as the main tool where mathematical software and the internet can be integrated. As argued by Eickelmann (2017), many of the schools in the present times are ill-equipped with application programs, mathematics software and digital content.

Schools in the developing countries do not have enough funds for technological integration in mathematics classes; hence, negative perception towards technology adoption is generated. Adoption of digital equipment and ICT facilities is essential to increase the readiness of schools to use technology in mathematics classes. It will improve the ratio between the number of computers and students, and make students and teachers interact with technological advancement. It is also important to provide mathematical software to the schools to improve the process of ICT integration in the teaching process (Eickelmann, 2017).

\section{Theme 7: Challenges from the perception of teachers}

ICT has become extremely important for improving the education system of the present world. Hence, it is critical to address the issues and challenges associated with the adoption of ICT in the teaching process. As argued by Ghavifekr et al. (2016), although teachers show acknowledge towards the adoption of technology in the education system, they continuously encounter different obstacles during the adoption process of technology in learning and teaching. Some of the major challenges that are associated with the integration of ICT in the teaching process are Limited accessibility, Limited ICT facilities, Lack of training and Lack of educator's competence.

These challenges in the education system affect the perceived usefulness of the teachers. As critiqued by Alkahtani (2017), the level of barriers or challenges differs from country to country. As an example, in economically developing countries, the competence of teachers is considered as the major barrier. The issues of ICT adoption can be seen mostly in the underdeveloped and developing countries due to lack of resources. Despite putting extreme effort into ICT integration in the education system, people in developing countries do not know how to use ICT tools. In developing countries, not every family has a computer system and internet facilities.

\section{Theme 8: Primary aspects of challenges of ICT adoption}

There are four major aspects of ICT adoption namely teaching preparation, knowledge, ICT training and school leadership that are affected by the potential challenges. The process of teaching preparation faces the issue of finding digital resources before every lesson. Due to lack of resources, teachers do not find the opportunity to prepare for the classroom teaching process. As a result, backup teaching is required to be developed by the teachers which take a lot of time. As critiqued by Ekberg \& Gao (2018), knowledge 
is a critical factor that influences the integration of ICT. Limited knowledge regarding the latest technology can be problematic technology adoption.

One of the most essential tools for integrating ICT in the schooling system is the training of teaching. However, most of the schools do not have an effective training process which is required for making the classroom environment constructive. Many schools in developed countries have professionally developed training programs. However, it is not enough to improve the competence of teachers. As cited by Blau \& Shamir-Inbal (2017), the leadership of the schools is needed to take the responsibility of integrating ICT with the teaching process. It is important for the school leadership to think about the teacher's professional development and pay attention to their needs and concerns.

\section{Theme 9: Opportunities for using ICT in mathematics class}

It has been found that many teachers face difficulties using ICT in the teaching process. On the other hand, it becomes challenging for the students to use it in the learning due to lack of resources and competence. As argued by Tachie (2019), teachers fail to pay attention to the opportunities of ICT that can be helpful for dealing with potential challenges. Based on the personal experience and the perception of teachers, the major opportunities have been identified. One of the biggest reasons behind the lack of competence of the teachers is the irregular use of ICT tools. Therefore, it is an opportunity to address the issue of competence by allowing the use of ICT on a regular basis.

It is also important for schools to set a budget for ICT and increase investment. It will be helpful for increasing the number of systems available in classes. The issue of a lack of a system can be tackled by bringing the computer and laptop of teachers in the classroom. The leaders of the school are needed to give the opportunity for teachers to bring their systems with them. As critiqued by Varshneya (2017), it is the responsibility of teachers to identify the ways of dealing with potential challenges. In order to do so, it is important to develop effective strategies and policies.

\section{Theme 10: Factors that prevent Malaysian teachersfrom adopting ICT}

Despite knowing the fact that ICT is beneficial for improving the education system, it is not widely used in the schools of Malaysia. There are five major factors that prevent the teachers of Malaysia from using ICT; they are lack of self-confidence, time constraints, lack of educational programs on ICT, lack of resources and negative attitude (Abdullah et al. 2016).

Presence of these aspects in the educational system of Malaysia has become the key issue for ICT integration. Malaysia is not an underdeveloped country; however, due to lack of seriousness the country is unable to go through the educational reforms. As discussed above, it is the responsibility of the teacher to identify the new ways of dealing with the present issues. As argued by Abdullah et al. (2016), it is not the responsibility of the teacher and students, but the education ministry and school administration should also promote the use of ICT in teaching and learning of mathematics. Based on the collaborative effort of everyone, the issue of technology adoption can be reduced to a certain level.

\section{Data collection}

Data collection techniques and tools are essential for developing the overall structure and finding of a research paper. In this present study, the data collection method of used articles is going to be discussed. As cited by Mulenga \& Phiri (2018), the data was collected through survey questionnaires using SPSS (Statistical Package for Social Science) method in the article of ICT adoption. However, in the study of Ifinedo, Saarela, \& Hämälänen (2019), the primary and secondary data has been collected through the TPACK framework to analyse the readiness of technological adoption. Besides, Mlambo, Chukwuere \& Ndebele (2018) has used questionnaires via Google in order to collect data regarding teachers ' perceptions of the adoption of ICT. 
Data collection method of Google form has helped the researcher to collect authentic data regarding the perception of teachers. As mentioned by Apeanti (2016), regarding the contributing factors of readiness of mathematics teachers, a cross-sectional survey method is used for data collection. The data collection has been done based on only one location at a time. According to (Kirkok \& Karanja, 2018), questionnaires and observation schedules method are used for the article based on the readiness of schools. As per Ghavifekr et al. (2016) in order to analyse the issues and challenges based on the perception of teachers, survey questionnaires were distributed among 120 teachers for a random survey.

One week of time was given to the teachers and after that, they returned the questionnaire. As per Ekberg \& Gao (2018), a qualitative data collection method with semi-structured interviews is used for identifying the challenges of ICT integration. As suggested by Njurai et al. (2017), integration survey and observation method is used in the article that shows the importance of using tablets in mathematics classes is shown using technology. As per Abdullah et al. (2016), survey questionnaires are the most useful method for getting information regarding most common challenges that are preventing teachers of Malaysia from adopting ICT. Moreover, Tachie (2019) has used open-ended questionnaires and interviews in the study regarding the opportunities of ICT adoption by the teachers of mathematics.

\section{Data summary and analysis}

In most of the schools analysing the data, it has been found that most of the schools do have any separate computer laboratories where ICT systems classes can be taken. According to the study by Kirkok \& Karanja (2018), maximum schools have two laboratories and in these schools, ICT systems can be incorporated. The study conducted by Eickelmann, Gerick \& Koop (2017), provides the result that less than $25 \%$ of the students do not know much application regarding usage of computers for understanding mathematics. The data analysis of this article has found a positive correlation between open mindedness of teachers regarding incorporation of new technologies. Data analysis has been conducted among 5 teachers and 5 learner participants to analyse challenges of opportunities for implementing ICT for mathematics teaching.

Issues regarding the incorporation of ICT in Malaysia can be found by evaluating a data analysis that the major issue is the time constraints with a standard deviation of 3.53 (Abdullah et al. 2016). Besides, the other issues are facility resources, supporting assistance and training of employees with a standard deviation value of 3.48 to 3.12. Data analysis of 138 samples was conducted to find the readiness of teachers for the integration of ICT systems. The data analysis was conducted to test the TPACK (Technological Pedagogical Content Knowledge) framework within the teaching method. The data analysis conducted by Ifinedo, Saarela \& Hämälänen (2019), showed that TK was associated with both $\operatorname{TCK}(\beta=0.32, \rho<0.001)$ and TPK $(\beta=0.48, \rho<0.001)$.

Data analysis of an article regarding the integration of ICT has found positive results where three consecutive tests in the first six months provide a result of improvement. The test result shows an improvement of $37.83 \%, 39.43 \%$ and $39.83 \%$ respectively. According to the study by Mlambo, Chukwuere \& Ndebele (2018), the data suggests that the most influencing factors for the teachers are their ICT knowledge, attitude to learning and perspective towards education.

\section{Review Result}

The result of the review of the articles suggests that most of the schools are having issues with the handling and managing of ICT systems (Chen et al. 2015). These schools do not have the required software, digital tools and application programs that can conduct effective mathematics classes with ICT systems. The resulting review of an article by Eickelmann, Gerick \& Koop (2017), suggested that the teachers are interested in incorporating new ways of teaching students. As discussed by Sobikwa \& Ditsa (2017), the teachers found it easy to demonstrate students the practical implementation of mathematics which is better for their future. The articles suggested that the procedure is going to be tough as most of 
the teachers do not have access to the computer labs. The result analysis of Abdullah et al. (2016) suggests that government and private institutions can take immediate efforts to fight with the constraints of introducing ICT.

The teachers are not much adequate to learn the new technologies and thus it is difficult for them to integrate ICT in their framework (Ifinedo, Saarela \& Hämälänen, 2019). Therefore, the readiness of teachers is not enough to adopt this technology. The article by Njurai et al. (2017) showed that incorporation of ICT systems for mathematics encouraged students. The students feel motivated and have fun while learning in an innovative way. As stated by Hains, Sedlar \& Cerepinko (2019), teachers are the most significant aspects for the incorporation of ICT system. As technology and methods of teaching are new, it is highly depending upon capabilities of learning among teachers. A study conducted by Ekberg \& Gao (2018), suggests that high time consumption and plagiarism in the work of students are the most significant challenges faced by the teachers.

Therefore, the review result of articles suggests that there are major issues in the teaching process using ICT systems. The critical review of article suggests that the interview, surveys and thematic analysis have highlighted the challenges as disadvantages are more than the advantages of ICT system for teaching and learning mathematics.

\section{Research Findings}

The research of integration of ICT in teaching and learning mathematics is focused on the issues and the teacher's readiness (Seeletse, 2016). The review of article suggested that there are many issues in the incorporation of ICT and most of these are tools and software related. As the teachers are not ready to learn new technologies, it is difficult to implement this plan.

The review is able to meet the aim of the study that is to find issues of the ICT integration systems and these are unavailability of software, inability to adopt new technologies and many more. The next aim is to find the readiness of teachers and it has been seen that the teachers are not ready to collaborate with new technologies. As depicted by Hallová, Polakovič \& Slováková (2017), the only advantage of ICT systems in learning mathematics found from the article review is that the interest development of students and increment of their motivation level.

\section{Recommendations}

Based on the above discussion the following have been recommended for improvement in teaching implications:

Teachers from all educational sectors should go through a training module process to learn the latest technologies regarding digital education systems. It is highly recommended that the educational sectors should organize training procedures regarding the incorporation of ICT to teach mathematics in schools. As discussed in the study by Kahloun \& Ayachi-Ghannouchi (2019), the training procedures will require findings to arrange trainers and digital equipment. It will generate confidence among teachers and they will get the opportunity to learn the usage of software, application programmes and digital tools. It is estimated that the training programme will require the time span of 3 to 5 months and the training should be done without interruption of general schooling procedures.

The education ministry should launch policies and regulations which can clarify the integration of ICT for teaching and learning mathematics. The policies should be implemented for both government and private institutions. According to Vazquez (2019), these policies may include teaching guidelines, qualification for teachers to participate in the programme and role of principle for the success of this new technology. It is expected to take around 6 months to plan effective policies and regulations. 
It is recommended that the software development company should focus on creating software and tools to promote ICT in teaching programmes. As the teachers and the students are novices in this new technology, the tools should be user friendly. They should make packages for schools and other educational sectors which include all the necessary equipment. As mentioned in the study by Fowler, Coffey \& Dixon-Fowler (2019), they should develop marketing campaigns for promoting their ICT teaching packages. Besides, they may contact the schools or via the government for promoting ICT systems for teaching. It is estimated that companies are going to take around 1 year to complete the project and campaigns.

\section{Conclusion}

It can be concluded based on the above discussion that the ICT process for teaching and learning of mathematics is comparatively new. Many education sectors are facing difficulties in adopting it. It has been found that the most significant issues are the software and digital tool related issues which are essential for integrating ICT systems. Besides, it has been found that teachers are not ready to learn new technologies and procedures of teaching as they are comfortable with the old techniques. The positive aspect found from the article review is the likeness of the students as their performance and motivations have increased by using ICT systems for learning mathematics. It is recommended that the government should implement policies for the schools regarding the integration of ICT, they should organize training for the teachers and software development companies should build user-friendly software.

\section{References}

Adofo, S. (2013). Challenges And Coping Strategies Of Student Nursing Mothers In Tertiary Institutions In The Greater Accra Region Of Ghana (M.Phil). University of Ghana.

Abdullah, A. H., Mokhtar, M., Kiong, J. C. C., Ali, M., Ibrahim, N. H., \& Surif, J. (2016, May). Factors preventing Malaysian teachers from using Information and Communication Technology (ICT) in teaching mathematics. In 2016 4th International Conference on Information and Communication Technology (ICoICT), 1-6.

Alkahtani, A. (2017). The challenges facing the integration of ICT in teaching in Saudi secondary schools. International Journal of Education and Development using ICT, 13(1).

Apeanti, W. O. (2016). Contributing Factors to Pre-Service Mathematics Teachers'e-Readiness for ICT Integration. International Journal of Research in Education and Science, 2(1), 223-238.

Blau, I., \& Shamir-Inbal, T. (2017). Digital competences and long-term ICT integration in school culture: The perspective of elementary school leaders. Education and Information Technologies, 22(3), 769-787.

Buabeng-Andoh, C. (2015). ICT usage in Ghanaian secondary schools: Teachers' perspectives. The International Journal of Information and Learning Technology, 32(5), 300-312.

Chen, A. N., McMurtrey, M., McCalman, D., Domínguez Castillo, J. G., \& Ligon, K. (2015). Information and communication technologies (ICT): Components, dimensions, and its correlates. Journal of International Technology and Information Management, 24(4), 25-45.

Daher, W., Baya'a, N., \& Anabousy, R. (2018). In-Service Mathematics Teachers' Integration of ICT as Innovative Practice. International Journal of Research in Education and Science, 4(2), 534-543.

Delavari, V., Shaban, E., Janssen, M., \& Hassanzadeh, A. (2019). Thematic mapping of cloud computing based on a systematic review: A tertiary study. Journal of Enterprise Information Management, 33(1), 161-190.

Eickelmann, B. (2017). Schule in der digitalen Welt-neue Aufgaben für Schulleitungen und Perspektiven für die Schulentwicklung. Vortrag im Rahmen der, 5.

Ekberg, S., \& Gao, S. (2018). Understanding challenges of using ICT in secondary schools in sweden from teachers' perspective. The International Journal of Information and Learning Technology, 35(1), 43-55. 
Fowler, E. A. R., Coffey, B. S., \& Dixon-Fowler, H. (2019). Transforming good intentions into social impact: A case on the creation and evolution of a social enterprise: JBE JBE. Journal of Business Ethics, 159(3), 665-678

Ghavifekr, S., Kunjappan, T., Ramasamy, L., \& Anthony, A. (2016). Teaching and Learning with ICT Tools: Issues and Challenges from Teachers' Perceptions. Malaysian Online Journal of Educational Technology, 4(2), 38-57.

Graham, M. A., Stols, G., \& Kapp, R. (2020). Teacher Practice and Integration of ICT: Why Are or Aren't South African Teachers Using ICTs in Their Classrooms. International Journal of Instruction, 13(2), 749-766.

Hains, V. V., Sedlar, A., \& Cerepinko, K. (2019). Competences And Methods Of Using Information And Communication Technology Amongst Pre-school And Primary School Teachers. Varazdin: Varazdin Development and Entrepreneurship Agency (VADEA).

Hallová, M., Polakovič, P., \& Slováková, I. (2017). Current trends in training of managers in the field of information and communication technologies and identifying the barriers to education of managers. AGRIS on-Line Papers in Economics and Informatics, 9(4), 45-52.

Hsin, C., Cheng, Y., \& Tsai, C. (2016). Searching and sourcing online academic literature. Online Information Review, 40(7), 979-997.

Ifinedo, E., Saarela, M., \& Hämälänen, T. (2019). Analysing the nigerian teacher's readiness for technology integration. International Journal of Education and Development using Information and Communication Technology, 15(3), 34-52.

Kahloun, F., \& Ayachi-Ghannouchi, S. (2019). A prototype for continuous improvement of processes and their results in the field of higher education. Business Process Management Journal, 26(1), 168-190.

Kim, S. (2018). ICT and the UN's sustainable development goal for education: Using ICT to boost the math performance of immigrant youths in the US. Sustainability, 10(12).

Kirkok, J., \& Karanja, D. (2018). Readiness of public secondary schools to integrate ict in mathematics teaching in mogotio sub-county of baringo county, kenya. Journal of Education and Practices ISSN 2617-5444 (ONLINE) \& ISSN 2617-6874 (PRINT), 1(1), 9-9.

Mlambo, S., Chukwuere, J. E., \& Ndebele, C. (2018). Perceptions of pre-service teachers on the use of ICTs for instructional purposes. Journal of Gender, Information and Development in Africa (JGIDA), 7(2), 77-101.

Mulenga, E.M. \& Phiri, P.A. (2018). Zambian teachers'profiles of ict use in mathematics pedagogy. Journal of Basic and Applied Research International, 24(4), 137-148.

Njurai, E., Stefansson, G., Jónsdóttir, A. H., Mwenda, P., Obonyo, M., \& Kariuki, J. (2017, June). Initial Reflections on Teaching and Learning Mathematics Using Tablets in a Prison Education Centre. In Paper presented at the 4th Strathmore International Mathematics Conference (SIMC 2016) 19, 23.

Ogundile, O. P., Bishop, S. A., Okagbue, H. I., Ogunniyi, P. O., \& Olanrewaju, A. M. (2019). Factors influencing ICT adoption in some selected secondary schools in Ogun State, Nigeria. International Journal of Emerging Technologies in Learning (iJET), 14(10), 62-74.

Qasem, A. A. A., \& Nathappa, V. (2016). Teachers'perception towards ict integration: professional development through blended learning. Main Issues Of Pedagogy And Psychology, 11(2), 20-26.

Schönreiter, I. M. (2018). Methodologies for process harmonization in the post-merger integration phase. Business Process Management Journal, 24(2), 330-356.

Seeletse, S. M. (2016). Information and communication technology as a primary tool for sefako makgatho health sciences University's statistics and operations research business. Problems and Perspectives in Management, 14(3), 115-122.

Senivongse, C., Bennet, A., \& Mariano, S. (2017). Utilizing a systematic literature review to develop an integrated framework for information and knowledge management systems: Very informal newsletter on library automation. VINE Journal of Information and Knowledge Management Systems, 47(2), 250-264.

Smirnov, E., \& Bogun, V. (2017). Information resources and communication technologies in teaching of mathematics at universities. International Journal of Economic Perspectives, 11(2), 795-801.

Sobikwa, D., \& Ditsa, G. (2017). The usage of gauteng online schools systems for basic education in soweto. Journal of Information Technology and Economic Development, 8(1), 1-24. 
DOI: https://doi.org/10.47405/mjssh.v5i12.582

Tachie, S. A. (2019). Challenges and opportunities regarding usage of computers in the teaching and learning of Mathematics. South African Journal of Education, 39(1).

Thennakoon, D., Bandara, W., French, E., \& Mathiesen, P. (2018). What do we know about business process management training? current status of related research and a way forward. Business Process Management Journal, 24(2), 478-500.

Varshneya, A. K. (2017). Distance Learning through ICT: Benefits and Challenges. Journal of Advanced Research in English \& Education, 2(3\&4), 6-9.

Vazquez, C. E. (2019). Successful work cultures: Recommendations for leaders in healthcare. Leadership in Health Services, 33(2), 296-308.

Werner, K., WRisko, N., WBurkholder, T., WMunge, K., WWallis, L., \& WReynolds, T. (2020). Costeffectiveness of emergency care interventions in low and middleincome countries: A systematic review. World Health Organization. Bulletin of the World Health Organization, 98(5), 341-352. 